Article

\title{
Trains in the Land of the Car: A Case Study of Mobility as Agency in the United States
}

\author{
Zinette Bergman 1,2 (D) \\ 1 Department of Psychology, University of the Witwatersrand, Johannesburg 2000, South Africa; \\ zinette.bergman@unibas.ch \\ 2 Department of Social Sciences, Social Research and Methodology Group, University of Basel, \\ Basel 4051, Switzerland
}

Received: 4 November 2019; Accepted: 25 November 2019; Published: 27 November 2019

\begin{abstract}
Recent studies have shown that self-efficacy—the belief that individuals are able to execute behaviors that lead to desired outcomes-is a key factor for adopting more sustainable travel modes and practices. Also crucial are societal values and policies associated with sustainability, which guide individual mobility behaviors. Thus, sustainable travel research and policies are divided into hard and soft approaches. This study applies Albert Bandura's concept of personal agency and his model of triadic reciprocal causation (TRC) to explore mobility as agency from the perspective of 32 car users from regions, which no longer have an adequate passenger rail infrastructure. The aim is to investigate the applicability of TRC theory in a US context, as well as a substantive study of how car users make sense of their mobility practices in relation to trains. Based on hermeneutic content analysis, a mixed-method analytic framework, findings reveal that Bandura's agentive pathways associated with individual and proxy agency define the mobility practices of interviewees. By exploring the underlying structures of salient agentive pathways, this study traces the links between agency and (un)sustainable travel within a US American mobility culture.
\end{abstract}

Keywords: sustainable travel; Albert Bandura; agency; model of triadic reciprocal causation (TRC); mixed methods; hermeneutic content analysis (HCA); multidimensional scaling (MDS); car users; trains; USA

\section{Introduction}

I've heard so many times that the reason we don't have them is because we're so big. And yet, all the rest of the world has trains and they're used all the time. (12: 14)

The main aim of sustainable travel is to reduce car use and to promote more sustainable modes of transportation [1-4]. Yet, mobility interventions are contingent on the ability and willingness of individuals to adopt new behaviors. Accordingly, individuals need to value sustainable travel and embrace relevant policies [5]. To achieve sustainable travel, research and policies tend to focus on hard and soft approaches. Hard approaches emphasize structural and regulatory interventions, such as developing or improving public transport, creating bicycle infrastructure, introducing road-pricing initiatives, or providing monetary incentives (see for example [6-9]). These strategies aim to nudge people toward more sustainable mobility practices, which in turn are aimed at reducing car use [10]. Soft approaches consist of cognitive-motivational interventions that target affect, beliefs, and attitudes to encourage adoption of sustainable behaviors [9,11-13]. Self-efficacy-the belief that individuals are able to execute behaviors that lead to desired outcomes-is a significant predictor of behavioral change [10]. In line with the soft approach, interventions often focus on reinforcing beliefs aligned with sustainable travel via group discussions, role-play, and information campaigns [14-16]. In recent years, 
many innovative projects have capitalized on evolving sustainability values, national or local policy frameworks that prioritize environmental concerns, or high-density cities with established or expanding public transport infrastructure to implement more sustainable travel (see for example $[9,10,14,17]$ ). However, what happens in contexts where the relevant values, policies, or infrastructure associated with sustainable travel are absent or have been superseded?

The United States lags far behind other developed nations in adopting sustainability measures, such as the Kyoto Protocol and the Paris Climate Agreement [18]. In large parts of the country, low-density, sprawling communities are the norm [5,19-21], and mobility of US Americans continues to be intertwined with private cars. Cars are synonymous with comfort [5], convenience [5,22], pleasure, freedom, satisfaction, and status [23-25]. According to Banister and colleagues [5] (p. 7), the car is culturally rooted: "Free roads, free parking, cheap petrol, and universal, cheap driver licensing are widely viewed as a natural right". Unsurprisingly, private car use continues to increase annually [26], average occupancy continues to decline [27], and as purchasing choices continue to shift toward light trucks and SUVs [28] it presents a formidable challenge to addressing the transport sectors' triple C's-climate change, congestion, and casualties $[1,17,29]$. The urgency for change is widely discussed $[1,5,20,21,30]$, yet investigations examining the agency potential for sustainable travel in the US context are rare. This study explores how car users in regions without developed passenger rail infrastructure in the US make sense of their mobility practices. The aims are to explore the potential of a sophisticated theoretical framework, Bandura's triadic reciprocal causation (TRC), to make relevant contributions to the study of sustainable travel, to explore how current mobility practices connect to more sustainable alternatives in the US, and to understand how links between agency and mobility policies relate to sustainable travel.

\section{Theoretical Background}

Mobility as agency offers a conceptual framework for linking personal agency to the mobility domain [31,32]. According to Albert Bandura's model of triadic reciprocal causation [33-36], individuals continuously negotiate ever changing environments because of their unique ability to "designedly conceive unique events and different novel courses of action and choose to execute one of them" [35] (p. 5). He termed this personal agency, and the conceptual dimensions and pathways of agency according to TRC are visualized in Figure 1.

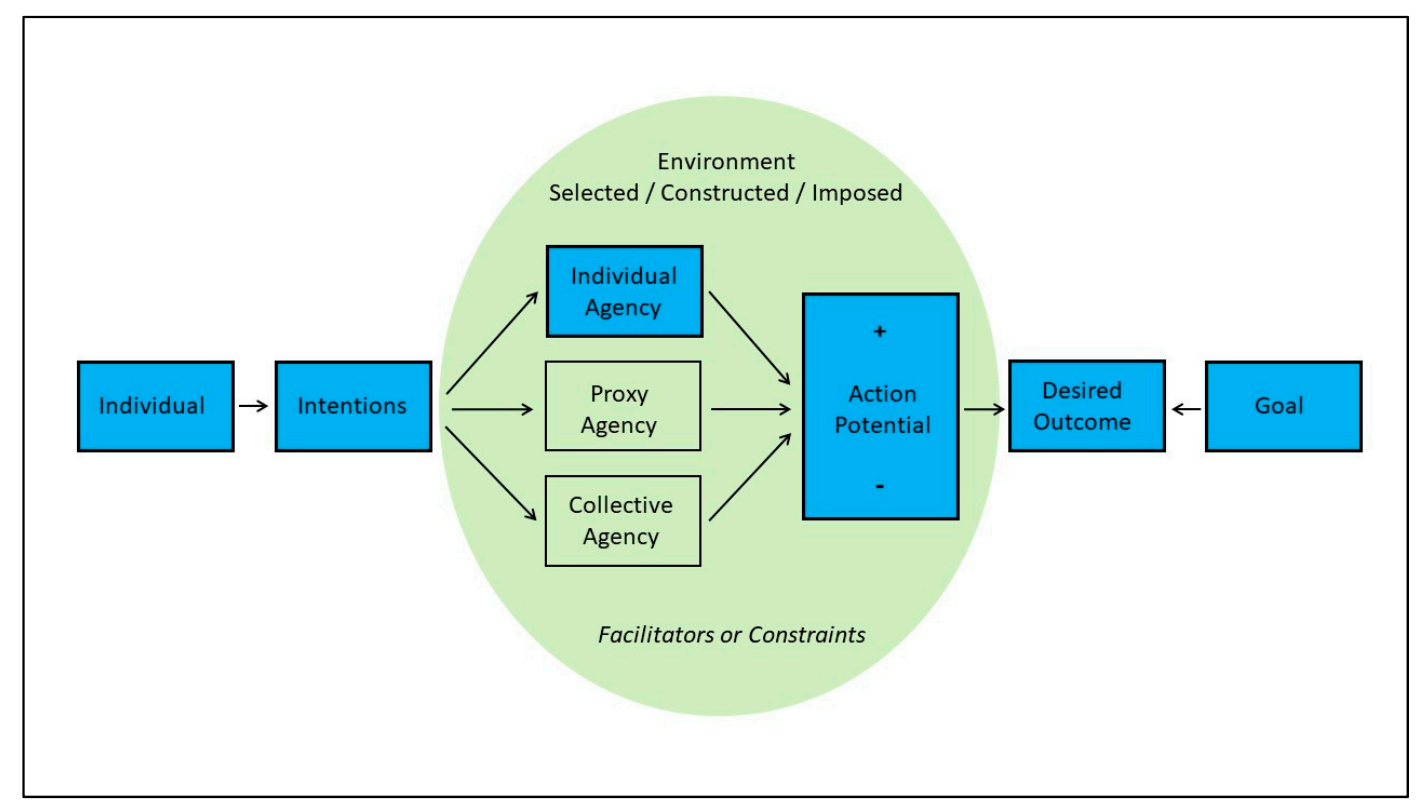

Figure 1. Personal agency according to Bandura's model of triadic reciprocal causation. 
Personal agency begins with the intentions to be mobile, which are the strategies or action plans individuals formulate to achieve a desired outcome [35,36]. Because intentions form the basis of future actions towards realizing a particular goal or desired outcome, intentions, goals, and desired outcomes are essentially the same but manifest at different points in time [35,36]. Actions separate our intentions in the present from achieving a desired outcome or goal in the future [31,32]. Turning intentions into goals involves various options and considerations. Bandura proposes three distinct modes of agency: Individual, proxy, and collective. Individual agency denotes the process whereby individuals guide their own behavior to achieve their goals [31,36]. Proxy agency refers to instances where someone else assists us in achieving our goals by acting on our behalf. Collective agency refers to situations where individuals work together to achieve their goals through interdependent effort [35,36].

Using a private car to reach a desired destination is an example of individual agency. Petitioning local government to develop public transport is an example of enlisting the help of a proxy to achieve mobility goals. Organizing a lift club or carpool are examples of collective agency-mobility goals are achieved through interdependent effort. The three modes of agency are embedded in, and dependent on, a range of environmental factors, which facilitate or constrain individuals' abilities to act. Bandura distinguished between selected, constructed, and imposed environments. A selected environment is characterized by choice. Here, individuals have access to a variety of options, such as a car, bus, and train, and they select the option that enables them to achieve their desired goal. The constructed environment does not exist in the present and thus requires concerted effort to create. Examples are campaigning for the development of public transport infrastructure or creating a car-pool community. The imposed environment introduces the most restriction. Here, individuals are constrained by their environment, and their action potential is limited to choosing whether to accept, protest, or move from one environment to another $[31,36]$. Examples are being unable to afford a car or being stuck in traffic.

Dimensions of agency and environment interact in complex ways, and they are managed through intra-personal deliberation [31,32]. In this process, individuals assess how environments, which are selected, constructed, or imposed, can facilitate or constrain their action potentials, and how they could utilize different modes of agency, such as individual, proxy, or collective agency, to achieve their goal. Individuals choose the mode of agency according to their understanding of a given environment, which is believed to secure a desired outcome [31,32,35]. According to TRC, an appropriate course of action is selected and implemented based on these complex and dynamic deliberations, as "internal personal factors in the form of cognitive, affective, and biological events, behavioral patterns, and environmental influences all operate as interacting determinants that influence one another" [36] (p. 6).

The highlighted agentive pathway in Figure 1 represents individual agency. Based on established research and the predominance of car-use in the US [5,20,22-25], we expect this agentive pathway to be the defining feature of mobility as agency in the US. However, how does this choice connect to agency and environment in relation to alternative modes of transport, especially trains? Specifically, two research questions guide this inquiry:

(1) What is mobility as agency from the perspective of car users in the US?

(2) How do trains specifically and sustainable travel more generally relate to their mobility choices?

\section{Materials and Methods}

Thirty-two narrative interviews were conducted with individuals residing in states that currently do not have a developed passenger rail infrastructure, including Arizona, Arkansas, Indiana, Michigan, Nevada, and Texas. Like most US Americans, interviewees are highly mobile, having grown up or lived in a number of other states. The age of the men $(n=15)$ and women ranged between 19 and 78 years $(m=38 ; s d=19)$. Interviewees occupied all socioeconomic strata and included homemakers, administrators, an artist, a construction worker, an electrician, a social worker, educators, a restaurant waiter, a bartender, an IT specialist, a soldier, security personnel, an account manager, small business owners, and retirees. While these interviewees are not representative of a larger population, the goal of this study is to assess the applicability of TRC, specifically how Bandura's 
concepts of agency and environment relate to US mobility contexts and culture. Interviewees were selected based on convenience or snowball sampling. Interviews were conducted immediately or at a time and place that was convenient for the researcher and interviewees. The interviews took place in cafes, restaurants, parks, university campuses, libraries, and other public places. Data were analyzed using hermeneutic content analysis (HCA) [37], a mixed-methods approach that has been employed in the fields of psychology, sociology, sustainability studies, business and management studies, business ethics and corporate sustainability, and mobility studies [31,32,38-40]. This method has also been used to study mobility in South Africa [31] and China [32]. HCA consists of three steps: The first, qualitative step consisted of identifying, sorting, and classifying agency and environment dimensions in accordance with Bandura's typology and as illustrated in detail in the first results section. To explore the interrelations between dimensions identified in the first step of HCA, a second, quantitative step, specifically multidimensional scaling (MDS), was performed. The similarity matrix of the co-occurrences of the dimensions was calculated using the Jaccard Index. Of the two most frequently used indices for similarity matrices of co-occurrence data (Association Strength and Jaccard) (see for example [41]), the latter provided the most stable solution with the least amount of stress. The analysis was based on thectar [42] and smacof [43] in R. A non-metric procedure with a primary approach to ties was used and the comparison was done at the code-level $(n=1071)$. At 0.06 , stress was much lower than for a random sample, estimated at 0.22 [44]. The findings from this analysis are presented in the second results section. To improve interpretation of the MDS results, the third step of HCA consists of a re-contextualization, where structures and patterns in the MDS map are interpreted with reference to the interview transcripts.

\section{Results}

\subsection{HCA Step 1: Linking Mobility as Agency to Mobility Practices}

The aim of the first analytic step was to connect Bandura's tripartite model to the mobility experiences of interviewees. This entailed identifying mobility-related vignettes in the data and their coding according to agency and environment dimensions as proposed by Bandura, which included intentions, types of agency and environments, environmental facilitators and constraints, action potentials, and desired mobility outcomes. The following is an illustrative example:

Interviewer: When you say a car is more convenient, why is that?

Interviewee: It's just, like I said, I guess not having one [a train] here, there was always just the car in the driveway as opposed to having to do something else. I guess you would have to take a car to get to where you would ride a train as well. So there are all those things, I don't know. I guess it's just more convenient to skip the train all together and take the car. Probably more costly cause you gotta pay for gas. (19: 4)

The mobility intention in this excerpt relates to convenience, but it also denotes the mobility goal because the interviewee's intended mobility choices and desired outcome are interrelated. The mode of agency is individual because agency is limited to the interviewee's own ability to act. Of the three types of environment proposed by Bandura (selected, constructed, and imposed), the lack of train infrastructure ("not having [a train] here") represents an imposed environment, while "to skip the train all together and take the car" exemplifies the ability to select the best environment. These environments link to constraints and facilitators. Not having access to a train, having to travel to the station before taking a train, and the costs associated with using a private car are examples of environmental constraints that contribute to a negative action potential. Always having a car in the driveway is exemplary of an environmental facilitator that supports a positive action potential, which enables the interviewee to achieve a desired outcome: To maximize convenience.

The agency and environment dimensions in the excerpt illustrate mobility as agency and exemplify the suitability of TRC as a theoretical framework. Overall, an analysis of 1071 mobility vignettes in 
the interviews revealed the following: First, the agency and environment dimensions as proposed in TRC adequately accounted for the mobility experiences of interviewees. Second, mobility experiences could be differentiated between individual, proxy, and collective modes of agency. Of these, individual and proxy agency dominated, while collective agency was only mentioned 12 times. When it occurred among the 1071 vignettes, it did not connect well to TRC because the collective in the data referred to shared experiences with family or friends while enjoying a train journey (especially touristic steam trains) or experiences in the interviewees' childhood. Thus, it could be argued that collective agency in Bandura's sense did not occur in the data. Finally, the two dominant dimensions of agency interconnected with the three dimensions of environment, representing complex, intra-personal deliberations as individuals assessed how various environments facilitated or constrained their potential to act, and how activating different modes of agency could help achieve desired mobility goals. The next analytic step examined how agentive pathways unfold across environments in the US mobility context.

\subsection{HCA Step 2: Mapping Agentive Pathways}

Multidimensional scaling (MDS) was used to map the relations between agency and environment dimensions as identified in step 1. Based on how frequently dimensions co-occur in the interviews, MDS visualizes the relationships in an $n$-dimensional space. In this step, the collective dimension was excluded on theoretical and methodological grounds because, as stated above, it was rarely mentioned by interviewees and because it did not match TRC's conceptualization of collective agency. In accordance with Bandura's tripartite model, the action potential and desired outcomes were divided into their positive and negative constituents ('action potential positive' and 'action potential negative', and 'desired outcome achieved' and 'desired outcome impeded'). The corresponding MDS map is presented below.

Figure 2 is an MDS map of mobility as agency from the perspectives of the interviewees. Each point in the map represents one of the dimensions associated with agency and environment as proposed by TRC. The distance between points represents the frequency with which dimensions co-occur in the interview data. The closer points are situated to one another in the MDS map, the more frequently the corresponding dimensions co-occur in the narratives, and the further apart the points, the less likely the dimensions co-occur. For example, the dimensions 'desired outcomes impeded' and 'negative action potential' located in the center of the cluster on the left are in close proximity, which means that the corresponding dimensions frequently related to one another in the narratives of interviewees. In contrast, the dimensions 'constructed environment', located at the top of the cluster on the left, and 'individual agency', located at the bottom of the cluster on the right, are maximally distant to one another, indicating that they rarely co-occurred in the narratives. The lines between points illustrate how dimensions cluster together. The line represents links between the most frequently co-occurring dimensions. The clustering of dimensions in MDS are interpretable and provide insight into the conceptual space of interviewees in ways that would not be possible through a qualitative analysis. 


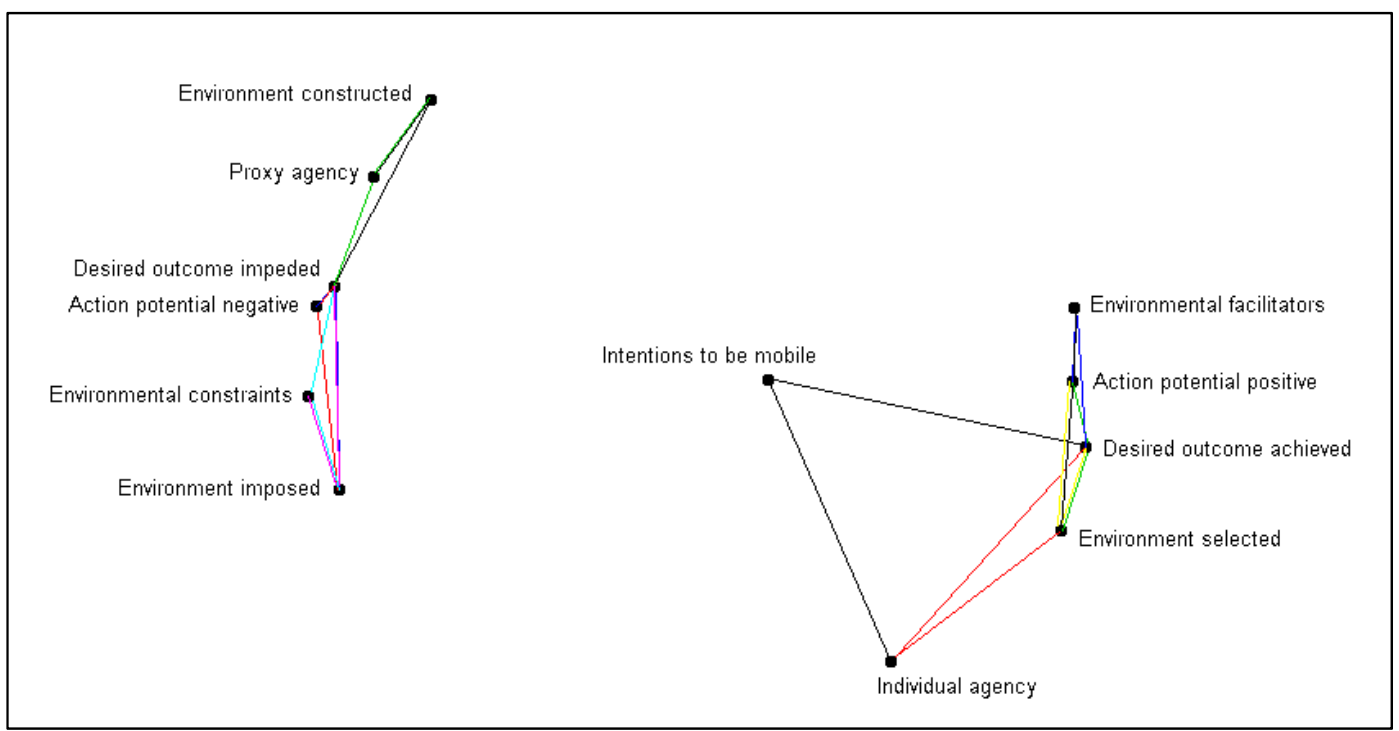

Figure 2. Multidimensional scaling (MDS) map of the agentive practices of car users in the US. Code-level comparison, $n=1071$, model parameters: A non-metric procedure, primary approach to ties, stress $=0.06$.

According to the MDS map, the TRC dimensions identified in step 1 form two distinct clusters, located on the left and right. The cluster on the left contains 'imposed environment', 'environmental constraints', 'negative action potential', 'impeded desired outcome', 'proxy agency', and 'constructed environment'. Two noteworthy characteristics define this cluster. First, it contains all negative dimensions associated with mobility: An imposed environment constrains the action potential of individuals to the extent that they are unable to achieve their desired mobility goals. Second, the negative dimensions are associated with proxy agency and a constructed environment: It is a proxy agent's failure to construct a viable environment that results in negative mobility outcomes. This agentive pathway represents the breakdown of mobility as the proxy imposes limits on the mobility environment, which results in a negative action potential and unattained mobility goals.

The cluster on the right contains the dimensions 'individual agency', 'selecting an environment', 'desired outcome achieved', 'facilitating environment', 'positive action potential', as well as 'intentions to be mobile'. In contrast to the cluster on the left, this cluster contains all positive dimensions associated with mobility: The ability to select between different mobility environments facilitates a positive action potential that helps secure desired mobility outcomes. The overall positivity of the cluster is associated with individual agency. This configuration indicates that mobility associated with individual agency consists of an agentive pathway, where interviewees are able to select between different mobility options to facilitate their mobility potential and desired mobility goals.

The central position of the dimension 'intentions to be mobile' in the MDS map indicates that it shares important relations with both clusters. In a sense, 'intentions to be mobile' forms a bridge between the positive individual and negative proxy pathway. The link to the individual agentive pathway represents the successful transition from mobility intentions to desired goals. The proximity between 'intentions to be mobile' and the negative proxy cluster on the left indicates that mobility intentions remain present but are unfulfilled by the proxy.

The final step of the analysis connects agentive pathways, as identified in the MDS map, to the narratives on the mobility experiences of interviewees.

\subsection{HCA Step 3: Mobility as Agency from the Perspective of Car Users in the US}

The proxy agentive pathway: A re-contextualization analysis of the mobility vignettes revealed that the proxy was mainly associated with the local and federal government, and that mobility references associated with government predominantly connected to passenger trains. Interviewees referred to 
either a lack of political will or public need to construct rail infrastructure in the areas where they live. This is due in part to trains being viewed as expensive and unprofitable, and government as inefficient and uninterested in investing into mobility infrastructure that would primarily benefit the poor, the elderly, or families. Here are some examples:

I keep hoping that they start laying more track. It's so damned political. When the West opened up, the land was here for the taking. It wasn't owned by anyone. So the railroads had their way of finding the easiest routes, but now it's a little more complex. I wish the government would get involved in this. Whether they, whatever they need to do, I think we need more railroads. (2: 1$)$

But because our city doesn't wanna bend. So you know, some people just don't wanna do what's best for a lot of people. (20: 2)

Yeah but it's like the rest, you know the train system is just a reflection of the rest of our infrastructure. Talk about it, talk about it, but never put enough money or time into it, you know. (7: 7)

The individual agentive pathway: The mobility vignettes associated with the individual agentive pathway predominantly concerned mobility expectations of individuals' daily mobility practices. Mobility expectations comprise three components: Convenience, comfort, and freedom of movement.

Convenience is associated with speed, flexibility, and affordability. Whatever the mode of transport, it should be fast and reach the intended destination within the shortest possible time. Mobility modes should be flexible, which means that they ought to work around the individual and their family's needs and activities including shopping, errands, and work and leisure. They should accommodate not only unique situations and lifestyles, but also momentary changes of plan. Finally, mobility modes should be cheap.

Beyond expectations of safety, comfort refers to access to wifi, food, entertainment, and beautiful scenery. Comfort is furthermore associated with personal space: Many interviewees place a premium on privacy to 'do whatever they want', listen to music as loudly as they like, and 'get in the zone'. They specifically dislike being in crowded places, or having to deal with negative, aggressive, or annoying people. In other words, a train journey should mimic as closely as possible the comfort, flexibility, and privacy of an idealized car journey - devoid of traffic jams, bad weather, or unwanted company.

Freedom of movement was mentioned most frequently. It denotes the ability to "go wherever you want, whenever you want" (18: 11), a phrase mentioned nearly verbatim by many. It represents at its core a desire for independence, spontaneity, immediacy, and individualism. Here are some examples:

So I would definitely not, no, I'm enough of an American that I would not give this up. I love the freedom. Like today, if I wanna go to town, I can. If I wanna go to Austin today, I can. It takes me twenty minutes to get everything together and go. (12: 8)

Interviewer: You mentioned earlier that you like to look at [trains] when they go by.

Interviewee: Yes, they fascinate me. You think of this idea of freedom. But in reality you lose your freedom. So there's a conflict. Maybe it's the possibility of freedom. You know, maybe it's the wrong word, freedom. Maybe it's adventure or wanderlust rather than freedom because this [she points to her vehicle] represents freedom. I can go wherever I like. And as long as I can afford the gas, I can go. (11: 8)

Intentions relating to convenience, comfort, and freedom of movement: Convenience, comfort, and freedom of movement form the basis for mobility expectations. It defines interviewees' intentions to be mobile and guides the strategies they use to select mobility options. Private car use becomes the paragon of mobility practices. It enables interviewees to do what they want, when they want, 
in exactly the way they want. This benchmark constitutes the expectations interviewees have of the role of the government. According to them, government would have the resources to prioritize the development of public transport infrastructure, and the government ought to provide convenient, fast, comfortable, easy-to-use, and cheap public transport. Here are two examples:

I think they should make it more accessible to people to be able to take trains. At the very least to make it more accessible for people to take it from city to city. I know you can't have a station in every little town, but I mean like College Station to San Antonio or to Dallas. Like I feel like that would be a lot better. That would be a lot more beneficial to people too because not everybody has a car and some people are just not gonna get on a plane. So I feel like that would be, give them-a lot of people a better option and give a lot of people like a better way to stay connected too. Yeah, so I definitely think it's a good idea to try to bring trains back. (11: 6)

... infrastructure maintenance you know that there are train systems and that they're kept up. That they are kept clean, that they're kept safe, that they're kept comfortable. Those things, but you know, again, of course they have to be affordable and now I am asking the impossible. I just don't see it any other way you know. I don't see a minimalist service that is not safe or clean. I don't see that working and I don't see a train system working that has all these wonderful things that is very expensive-working so it's some kind of magic. A magic compromise that maybe train decision makers have to work on. This magic, how to make this magic work? (28: 18)

On the one hand, the above excerpts illustrate how interviewees use their mobility benchmark to evaluate other modes of transportation. Essentially, interviewees would like to transpose all the comfort, convenience, and freedom in their private cars onto trains. On the other hand, they consider it the government's responsibility to create a mobility environment, which includes comfort, convenience, and freedom across multiple mobility modes. Where does this benchmark of mobility expectations come from, and why is the maintenance of this benchmark the responsibility of the government? This final excerpt traces the origins and perpetuation of such mobility expectations:

I think it goes back to the 50s and earlier, cause it wasn't until the late 40s, early 50s that I remember a lot of people having cars. You know, during the war you couldn't get a car. Basically, before that, during the depression, a lot of people couldn't afford it, and in the 50s, you know, Eisenhower started to build the interstate system, made travelling throughout the country easier. The car companies came out with reasonably priced, nice cars that the average family could afford, and everybody found that freedom of movement. (7: 9)

Historically the government created a mobility environment that enabled convenience, comfort, and freedom of movement to serve an increasingly individualistic and consumer-oriented society. In the process, it also created the most formidable economy in the world. Over time and through institutionalization, individuals appropriated this benchmark: To own the freedom of movement, which maximizes individual expressions of taste and lifestyle, as well as personal comfort and convenience. Convenience, comfort, and freedom became the quintessential cultural markers in the US, including and transcending individual mobility practices.

\section{Discussion and Conclusions}

The aims of this study were to explore the potential of TRC as a theoretical framework for studying the links between agency and mobility practices, to make a relevant contribution to the study of sustainable travel, to explore how current mobility practices connect to more sustainable alternatives in the US, and to understand how links between agency and mobility policies relate to sustainable travel. 
Mobility as agency constitutes two distinct agentive pathways: One connected negatively to a proxy and the other connected positively to individual agency. Interestingly, collective agency as proposed by TRC is largely absent among US car users. The government as a proxy agent is ostensibly incapable or unwilling to invest in appropriate public transport infrastructure, which imposes limits to the US mobility environment. Many participants are critical of the government's failure to develop mobility infrastructure that would benefit either themselves or, to a limited extent, society. The latter is synonymous with the poor, the elderly, and families.

The failure of agency derived from the proxy contrasts with the positivity of individual agency as associated with individual expectations, goals, and practices. Here, individual agency is embedded in encultured mobility expectations-comfort, convenience, and freedom, which guide interviewees' assessment of and selection between different mobility modes. This benchmark ostensibly enables individuals to 'do what they want, when they want, in exactly the way they want'.

The primary contribution of this study relates to how this benchmark defines individual and proxy agency in relation to mobility as agency. The horizon of mobility choices and their practice is limited by comfort, convenience, and freedom. Just as collective agency did not feature in how interviewees conceptualize mobility as agency, so is sustainability or sustainable travel absent in daily mobility thought and practices because both would fail the benchmark assessment. Instead, the mobility domain is constrained by mobility modes which best secures or exceed benchmark expectations: Does a possible mobility alternative improve on the convenience, comfort, and freedom of an idealized car journey? The role of the government is limited in that it is relegated to the development, provision, and maintenance of a mobility environment that aligns with this benchmark. The failure of the government is not the inability to provide access to passenger trains, but a failure to extend the mobility benchmark to other modes of transport. According to this logic, the potential for behavior change to more sustainable practices are conditional on the basis that (a) modalities fulfill these benchmark requirements and (b) the government provides alternative mobility modes to individuals without interrupting lifestyles and at no extra cost. In the present and near future, trains in the US are understood as an occasional travel alternative, not a replacement of cars.

This has profound implications on the potential for sustainable travel, which is dependent on the societal embeddedness of sustainability values on the one hand, and policy interventions to implement sustainable travel on the other. While interviewees apparently desired access to trains, the support for extending public transport infrastructure is expected to conform to benchmark expectations. The consequences on designing soft approaches to change mobility behavior in this context are significant. While most studies have emphasized reinforcing or aligning beliefs and values with sustainable travel through group discussion, role-play, and information campaigns [14-16], the findings indicate that sustainability values will be subordinated to benchmark expectations for the near future. Hard approaches such as developing public transport infrastructure that fulfill the prevalent benchmark become a prerequisite for change in the mobility domain. This context encourages especially elected decision makers to continue investing in existing, car-centric infrastructure, and a disincentive to explore sustainable alternatives. But even if sustainable travel enjoyed greater public and political support, the vast, low-density landscape in the US presents a formidable challenge to develop large-scale public transport infrastructure. Of course, the same could be said about China, the current world champion in public transport infrastructure development, but its historical and cultural roots are very different, as are the position on a socioeconomic development trajectory, public expectations, and governance model. The question of how to make mobility in the US context sustainable is something that research and policy have not addressed adequately. For now, the most feasible solutions depend on technological innovation that do not interfere with predominant travel preferences, identity markers, or lifestyles of US Americans [5], nudging models that do not enjoy public or political support, or information campaigns that seem ineffective for now. The absence of more sustainable alternatives, the disincentives against developing them, and the presence of existing institutionalized norms and values create a stalemate. 
In some sense, the current divisive political landscape in the US reflects on a grand scale what is observed in a microcosm. A conflict wherein the old untenable and unsustainable world imposes its values and rules on a new world that, still nameless and shapeless, is becoming more present with each political and climate emergency. Faced with rapid economic, social, political, and environmental changes, politics and society retreat into familiar comforts. For the car users who participated in this study, addiction to comfort, convenience, and an imagined sense of freedom limits their ability to reimagine lifestyles and consumption. Thus, even when asked about an imagined, ideal future, their addictions define mobility along the contours of the past 70 years. Yet, finite resources, the increasing frequency and significance of climatic events, and its consequences require significant adaptation from individuals and societies. The world must find ways to travel more sustainably, and, for better or worse, the US will continue to play a disproportionate role in the 21st century.

Funding: This research received no external funding.

Acknowledgments: The author would like to thank the Mobile Loves Forum for making this research possible and Manfred Max Bergman for his helpful comments on a previous version of the manuscript.

Conflicts of Interest: The author declares no conflict of interest.

\section{References}

1. Bergman, Z.; Bergman, M.M. A Case Study of the Sustainable Mobility Problem-Solution Paradox: Motility and Access of Metrorail Commuters in the Western Cape. Sustainability 2019, 11, 1-17. [CrossRef]

2. Black, W.R. Sustainable Transportation: Problems and Solutions, 1st ed.; The Guilford Press: New York, NY, USA, 2010.

3. Ettema, D.; Gärling, T.; Olsson, L.E.; Friman, M.; Moerdijk, S. The road to happiness: Measuring Dutch car drivers' satisfaction with travel. Transport Policy 2013, 27, 171-178. [CrossRef]

4. Proost, S.; Dender, K.V. Optimal urban transport pricing in the presence of congestion, economies of density and costly public funds. Transp. Res. Part A Policy Pract. 2008, 42, 1220-1230. [CrossRef]

5. Banister, D.; Pucher, J.; Lee-Gosselin, M. Making Sustainable Transport Politically and Publically Acceptable: Lessons from the EU, USA, and Canada. In Institutions and Sustainable Transport: Regulatory Reform in Advanced Economies; Rietveld, P., Stough, R., Eds.; Edward Elgar Publishing: Cheltenham, England, 2007; pp. $17-50$.

6. Tillema, T.; van Wee, B.; Ettema, D. Road Pricing and Relocation Decisions of Dutch Households. Urban Stud. 2010, 47, 3013-3033. [CrossRef]

7. Arnott, B.; Rehackova, L.; Errington, L.; Sniehotta, F.F.; Roberts, J.; Araujo-Soares, V. Efficacy of behavioural interventions for transport behaviour change: systematic review, meta-analysis and intervention coding. Int. J. Behav. Nutr. Phys. Act. 2014, 11, 133. [CrossRef] [PubMed]

8. Herring, H.; Roy, R. Technological innovation, energy efficient design and the rebound effect. Technovation 2007, 27, 194-203. [CrossRef]

9. Cellina, F.; Bucher, D.; Mangili, F.; Simão, J.V.; Rudel, R.; Raubal, M. A Large Scale, App-Based Behaviour Change Experiment Persuading Sustainable Mobility Patterns: Methods, Results and Lessons Learnt. Sustainability 2019, 11, 2674. [CrossRef]

10. Skarin, F.; Olsson, L.E.; Friman, M.; Wästlund, E. Importance of motives, self-efficacy, social support and satisfaction with travel for behavior change during travel intervention programs. Transp. Res. Part F Traffic Psychol. Behav. 2019, 62, 451-458. [CrossRef]

11. Steg, L.; Tertoolen, G. Sustainable Transport Policy: The Contribution from Behavioural Scientists. Public Money Manag. 1999, 19, 63-69. [CrossRef]

12. Graham-Rowe, E.; Skippon, S.; Gardner, B.; Abraham, C. Can we reduce car use and, if so, how? A review of available evidence. Transp. Res. A Policy Pract. 2011, 45, 401-418. [CrossRef]

13. Chatterjee, K.; Bonsall, P. Editorial for special issue on "Evaluation of programmes promoting voluntary change in travel behaviour". Transp. Policy 2009, 16, 279-280. [CrossRef]

14. Olsson, L.E.; Huck, J.; Friman, M. Intention for Car Use Reduction: Applying a Stage-Based Model. Int. J. Environ. Res. Public Health 2018, 15, 216. [CrossRef] 
15. Diniz, I.M.S.; Maria de Fátima, S.D.; Peres, K.G.; de Oliveira, E.S.A.; Berndt, A. Active Commuting by Bicycle: Results of an Educational Intervention Study. J. Phys. Act. Health 2015, 12, 801-807. [CrossRef] [PubMed]

16. Rose, G. Encouraging Sustainable Campus Travel: Self-Reported Impacts of a University TravelSmart Initiative. J. Public Transp. 2008, 11, 85-108. [CrossRef]

17. Olsson, L.E.; Maier, R.; Friman, M. Why Do They Ride with Others? Meta-Analysis of Factors Influencing Travelers to Carpool. Sustainability 2019, 11, 1-16. [CrossRef]

18. Zhang, Y.X.; Chao, Q.C.; Zheng, Q.H.; Huang, L. The withdrawal of the U.S. from the Paris Agreement and its impact on global climate change governance. Adv. Clim. Chang. Res. 2017, 8, 213-219. [CrossRef]

19. Urry, J. Automobility, Car Culture and Weightless Travel: A Discussion Paper; Lancaster University: Lancaster, UK, 1999.

20. Urry, J. The 'System' of Automobility. Theory Culture Society 2004, 21, 25-39. [CrossRef]

21. De las Heras-Rosas, C.J.; Herrera, J. Towards Sustainable Mobility through a Change in Values. Evidence in 12 European Countries. Sustainability 2019, 11, 4274. [CrossRef]

22. Westman, J.; Friman, M.; Olsson, L.E. What Drives Them to Drive?-Parents' Reasons for Choosing the Car to Take Their Children to School. Front. Psychol. 2017, 8, 1970. [CrossRef]

23. Jakobsson, C. Instrumental Motives for Private Car Use. In Threats from Car Traffic to the Quality of Urban Life; Gärling, T., Steg, L., Eds.; Elsevier: Oxford, UK, 2007; pp. 205-217.

24. Steg, L. Car use: lust and must. Instrumental, symbolic and affective motives for car use. Transp. Res. Part A Policy Pract. 2005, 39, 147-162. [CrossRef]

25. Mokhtarian, P.; Salomon, I. How Derived is the Demand for Travel? Some Conceptual and Measurement Considerations. Transp. Res. A Policy Pract. 2001, 695-719. [CrossRef]

26. Deloitte 2019 Global Automotive Consumer Study Consumer Trends in the Automotive Industry. Available online: https://www2.deloitte.com/content/dam/Deloitte/us/Documents/manufacturing/us-globalautomotive-consumer-study-2019.pdf (accessed on 26 November 2019).

27. Van Dender, K.; Clever, M. OECD Recent Trends in Car Usage in Advanced Economies—Slower Growth Ahead? Discussion Paper; International Transport Forum: Paris, France, 2013; pp. 1-24.

28. Bailo, C.; Dziczek, K.; Smith, B.; Spulber, A.; Chen, Y.; Schultz, M. The Great Divide: What Consumers Are Buying vs. The Investments Automakers \& Suppliers Are Making in Future Technologies, Products $\mathcal{E}$ Business Models; Center for Automotive Research: Ann Arbor, MI, USA, 2018; pp. 1-33.

29. Geerken, T.; Vercalsteren, A.; Borup, M. Review of the mobility domain. In System Innovation for Sustainability 2: Case Studies in Sustainable Consumption and Production-Mobility; Geerken, T., Borup, M., Eds.; Greenleaf Publishing Limited: Sheffield, UK, 2009; pp. 6-26.

30. Banister, D. Cities, mobility and climate change. J. Transp. Geogr. 2011, 19, 1538-1546. [CrossRef]

31. Bergman, Z.; Bergman, M.M.; Thatcher, A. Agency and Bandura's Model of Triadic Reciprocal Causation: An Exploratory Mobility Study Among Metrorail Commuters in the Western Cape, South Africa. Front. Psychol. 2019, 10, 411. [CrossRef]

32. Bergman, Z.; Bergman, M.M.; Haenggi, C.; Lei, Z.; Thatcher, A. Technological change and sociocultural models in China: A case study of train users living in Beijing. Mobilities. Forthcoming.

33. Bandura, A. Social Foundations of Thought and Action: A Social Cognitive Theory; Prentice-Hall, Inc.: Englewood Cliffs, NJ, USA, 1986.

34. Bandura, A. Human agency in social cognitive theory. Am. Psychol 1989, 44, 1175-1184. [CrossRef] [PubMed]

35. Bandura, A. Social cognitive theory: An agentic perspective. Annu. Rev. Psychol 2001, 52, 1-26. [CrossRef] [PubMed]

36. Bandura, A. Toward a Psychology of Human Agency. Perspect. Psychol. Sci. 2006, 1, 164-180. [CrossRef]

37. Bergman, M.M. Hermeneutic Content Analysis: Textual and Audiovisual Analyses within a Mixed Methods Framework. In SAGE Handbook of Mixed Methods in Social \& Behavioral Research; SAGE Publications, Inc.: Thousand Oaks, CA, USA, 2010; pp. 379-396.

38. Bergman, M.M.; Berger, L.; Leisinger, K.; Zhang, J.; Liu, B.; Bergman, Z. How well do Chinese corporate responsibility expectations map onto an international corporate responsibility scale? UWF 2015, 23, 191-196. [CrossRef]

39. Bergman, M.M.; Berger, L.; Leisinger, K.; Bergman, Z.; Liu, B.; Zhang, J. Corporate Responsibility Expectations in China: Advanced Business and Economics Students from Beijing. In Sustainable Business, Management, and Economics; Bergman, M.M., Ed.; MDPI: Basel, Switzerland, 2017. 
40. Bergman, Z.; Bergman, M.M.; Fernandes, K.; Grossrieder, D.; Schneider, L. The Contribution of UNESCO Chairs toward Achieving the UN Sustainable Development Goals. Sustainability 2018, 10, 4471. [CrossRef]

41. Borg, I.; Groenen, J.F.; Mair, P. Applied Multidimensional Scaling; Springer: New York, NY, USA, 2012.

42. Berger, L. thectar: Tools for Hermeneutic Content Analysis in R. Forthcoming.

43. Mair, P.; de Leuuw, J.; Groenen, P.J.F. Multidimensional Scaling in R: SMACOF. Available online: https://pdfs. semanticscholar.org/5785/b73b48c4549ed776af5027aa602b5fce7758.pdf (accessed on 26 November 2019).

44. Spence, I. A Simple Approximation for Random Rankings Stress Values. Multivar. Behav. Res. 1979, 14, 355-365. [CrossRef]

(C) 2019 by the author. Licensee MDPI, Basel, Switzerland. This article is an open access article distributed under the terms and conditions of the Creative Commons Attribution (CC BY) license (http://creativecommons.org/licenses/by/4.0/). 